\title{
Erratum: Effect of Several Native Moss Plants on Particulate Matter, Volatile Organic Compounds and Air Composition
}

\author{
Gyeong Yeop Gong' ${ }^{2}$, Ji Su Kang², Kyeong Jin Jeong' ' Jun Ho Jeong ${ }^{3}$, and Jae Gill Yun ${ }^{1 *}$ \\ 'Department of Horticulture Science, Gyeongnam National University of Science and Technology, Jinju 52725, Korea \\ ${ }^{2}$ Graduate, Gyeongnam National University of Science and Technology, Jinju 52725, Korea \\ ${ }^{3}$ Eco People Corporation, Seoul 05098, Korea
}

Journal of People, Plants, and Environment 22(1):31-38; https://doi.org/10.11628/ksppe.2019.22.1.031;

published February 28, 2019

Correction: This research was supported by Gyeongnam National University of Science and Technology in 2017. 